\title{
Molecular Dynamics Simulations of the Interaction of Mouse and Torpedo Acetylcholinesterase with Covalent Inhibitors Explain Their Differential Reactivity: Implications for Drug Design Nellore Bhanu Chandar, ${ }^{1}$ Irena Efremenko, ${ }^{1}$ Israel Silman, ${ }^{2}$ Jan M.L. Martin, ${ }^{1}$ and Joel L. Sussman ${ }^{3}$ \\ (1) Dept. of Organic Chemistry, Weizmann Institute of Science, 7610001 Rehovot, Israel. Email: gershom@weizmann.ac.il Dept. of Neurobiology, Weizmann Institute of Science, 7610001 Rehovot, Israel, Email: Israel.Silman@weizmann.ac.il Dept. of Structural Biology and Israel Center for Structural Proteomics, Weizmann Institute of Science, 7610001 Rehovot, Israel. Email: joel.sussman@weizmann.ac.il
}

\begin{abstract}
:
Although the three-dimensional structures of mouse and Torpedo californica acetylcholinesterase are very similar, their responses to the covalent sulfonylating agents benzenesulfonyl fluoride and phenylmethylsulfonyl fluoride are qualitatively different. Both agents inhibit the mouse enzyme effectively by covalent modification of its activesite serine. In contrast, whereas the Torpedo enzyme is effectively inhibited by benzenesulfonyl fluoride, it is completely resistant to phenylmethylsulfonyl fluoride. A bottleneck midway down the active-site gorge in both enzymes restricts access of ligands to the active site at the bottom of the gorge. Molecular dynamics simulations revealed that the mouse enzyme is substantially more flexible than the Torpedo enzyme, suggesting that enhanced 'breathing motions' of the mouse enzyme relative to the Torpedo enzyme might explain why phenylmethylsulfonyl fluoride can reach the active site in mouse acetylcholinesterase, but not in the Torpedo enzyme. Accordingly, we performed docking of the two sulfonylating agents to the two enzymes, followed by molecular dynamics simulations. Whereas benzenesulfonyl fluoride closely approached the active-site serine in both mouse and Torpedo acetylcholinesterase in such simulations, phenylmethylsulfonyl
\end{abstract}


fluoride was able to approach the active-site serine of mouse acetylcholinesterase - but remained trapped above the bottleneck in the case of the Torpedo enzyme. Our studies demonstrate that reliance on docking tools in drug design can produce misleading information. Docking studies should, therefore, also be complemented by molecular dynamics simulations in selection of lead compounds.

\section{Author summary}

Enzymes are protein molecules that catalyze chemical reactions in living organisms, and are essential for their physiological functions. Proteins have well defined threedimensional structures, but display flexibility; it is believed that this flexibility, known as their dynamics, plays a role in their function. Here we studied the neuronal enzyme acetylcholinesterase, which breaks down the neurotransmitter, acetylcholine. The active site of this enzyme is deeply buried, and accessed by a narrow gorge. A particular inhibitor, phenylmethylsulfonyl fluoride, is known to inhibit mouse acetylcholinesterase, but not that of the electric fish, Torpedo, even though their structures are very similar. A theoretical technique called molecular dynamics (MD) shows that the mouse enzyme is more flexible than the Torpedo enzyme. Furthermore, when the movement of the inhibitor down the gorge towards the active site is simulated using MD, the phenylmethylsulfonyl fluoride can reach the active site in the mouse enzyme, but not in the Torpedo enzyme, in which it remains trapped midway down the gorge. Our study emphasizes the importance of taking into account not only structure, but also dynamics, in designing drugs targeted towards proteins. 


\section{Introduction:}

The principal biological role of acetylcholinesterase $(\mathrm{AChE})$ is termination of transmission at cholinergic synapses by rapid hydrolysis of the neurotransmitter, acetylcholine (ACh) $[1,2]$.

The crystal structure of $T c \mathrm{AChE}$ revealed that, despite the high catalytic activity of AChE, which approaches diffusion control [3], its active site is near the bottom of a long and narrow gorge, > $15 \AA$ long, a large part of the surface of which is lined by aromatic residues [4]. Near the mid-point of the gorge is a bottleneck, between two conserved aromatic residues, whose cross-section is smaller than the diameter of the quaternary group of ACh, $6.4 \AA$. Thus, in TcAChE, the cross-section at the narrowest point of the bottleneck is $\sim 5 \AA$ [4]. In mAChE, the narrowest point of the bottleneck has a cross-section of $2.4 \AA$ [5] . Fig 1 displays the crystal structure of the complex with ACh of the S203A mutant of mAChE. Space-filling representations of two ACh molecules are seen, one lodged above the gorge, and one below it [6]. This representation clearly illustrates that the AChE molecule needs to 'breathe' substantially in order for the ACh molecule to pass through the bottleneck to reach the active site.

$\mathrm{AChE}$ is the target of a repertoire of inhibitors that act by covalent modification of its active-site serine. These include organophosphate (OP) nerve agents, and both OP and carbamate insecticides [7]. Phenylmethylsulfonyl fluoride (PMSF) is a sulfonylating agent commonly employed as a non-specific inhibitor of serine proteases [8]. It was reported by Fahrney \& Gold [9] that Electrophorus electricus AChE is resistant to inhibition by PMSF, 
although it was later reported that it is indeed inhibited, but extremely slowly [10]. It was subsequently shown that mammalian AChEs are very susceptible to inhibition by PMSF $[11,12]$.
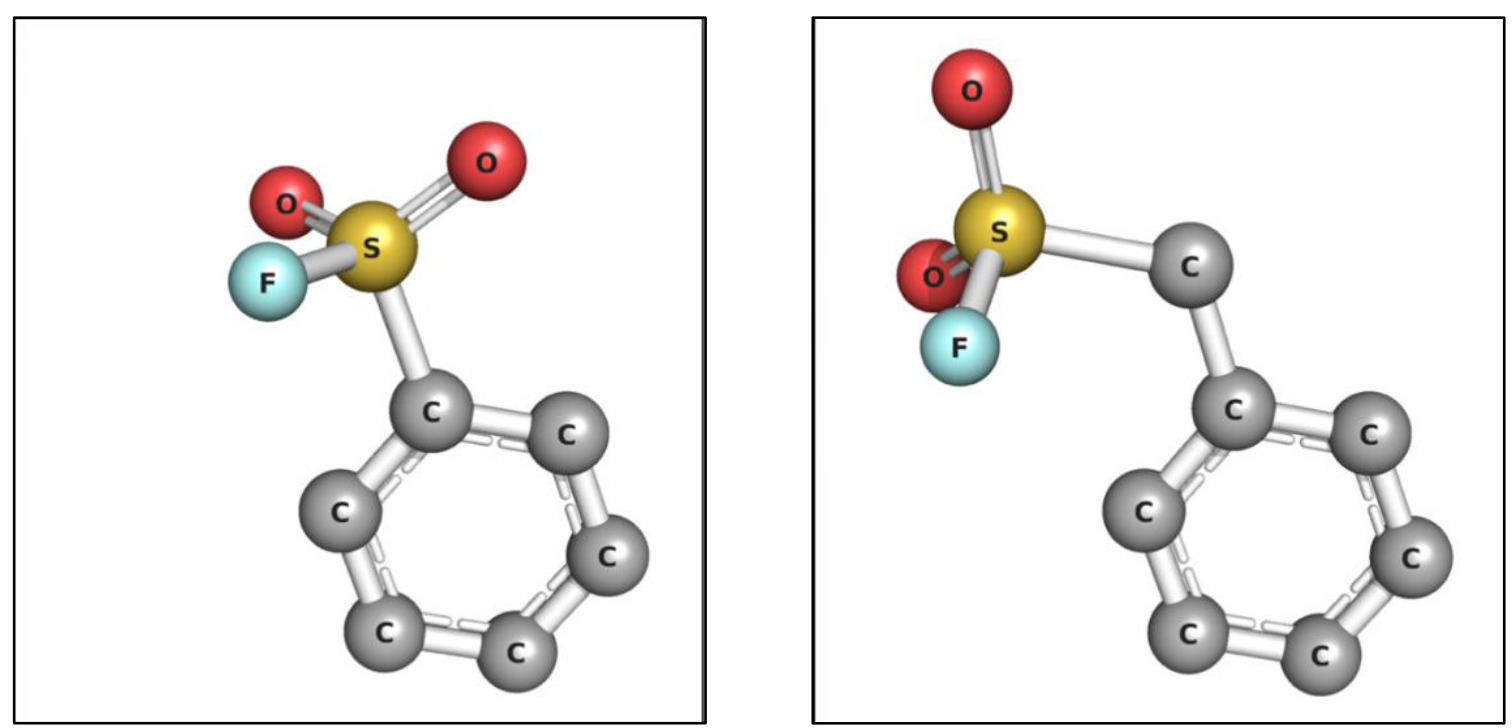

Scheme 1: Stick representations of benzenesulfonyl fluoride (BSF, left) and phenylmethylsulfonyl fluoride (PMSF, right) (see S1 Fig in Supplementary Information).

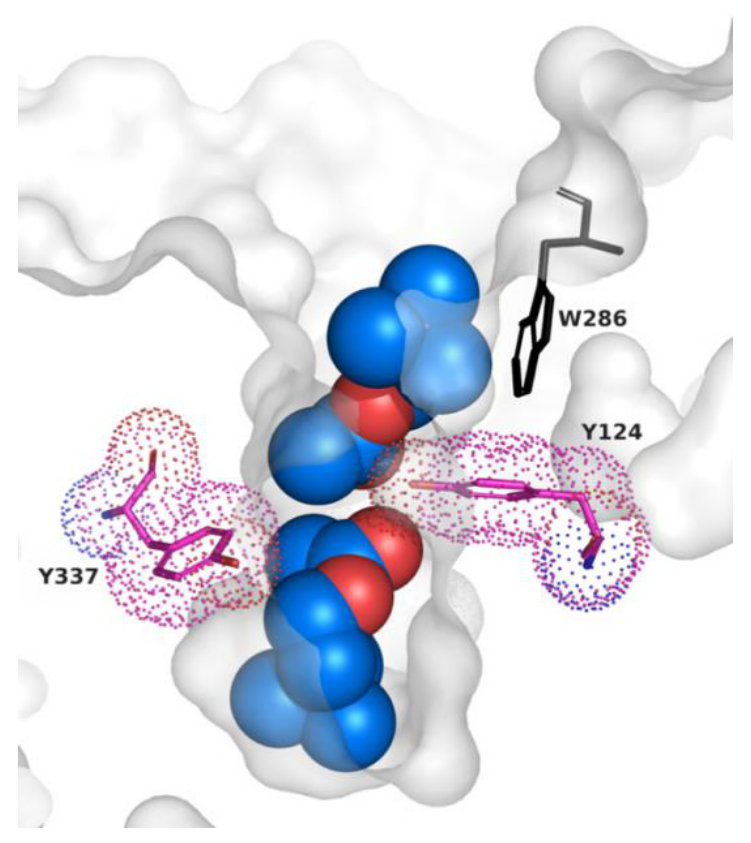

Fig 1. Space-filling representations of two ACh molecules in the active-site gorge of mAChE. The illustration is based on the PDB ID 2HA4 crystal structure [6]. The two AChs 
are positioned above and below the bottleneck residues, Y337 and Y124, which are displayed as sticks, with magenta dots displaying their full space-filling surface; the surface of the gorge as a whole is displayed in grey.

In an earlier study, we reported that $\mathrm{AChE}$ from the electric organ of another electric fish, Torpedo californica $(T c) \mathrm{AChE}$, is also resistant to PMSF, but is irreversibly inhibited very effectively by its homolog benzenesulfonyl fluoride (BSF) (Scheme 1) [13]. In contrast, we found that mouse $\mathrm{AChE}(\mathrm{mAChE})$ is very well inhibited by both PMSF and BSF. These observations are puzzling because the crystal structures of TcAChE [4] and mAChE [14] are very similar (Fig 2), as are the kinetic constants for their extremely rapid action on their natural substrate, ACh, and on its homolog, acetylthiocholine $[15,16]$. We subsequently reported that the anti-Alzheimer drug, rivastigmine (Exelon ${ }^{\mathrm{TM}}$ ), carbamylates human AChE >1,600-fold faster than TcAChE [17]. 


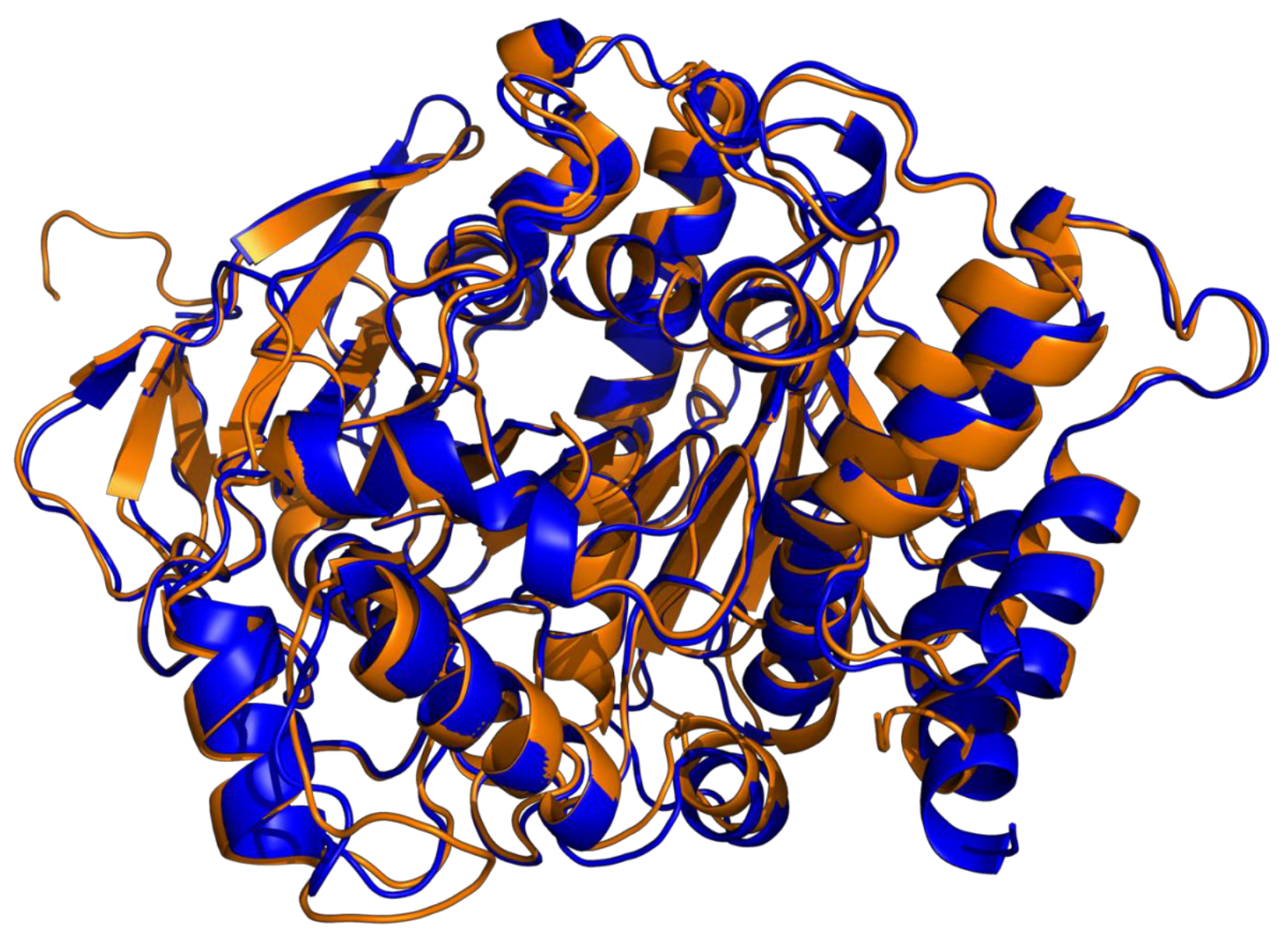

Fig 2. Overlay of cartoon representations of the crystal structures of $T c \mathrm{AChE}$ (blue) and mAChE (orange) looking down the active-site gorge.

In the following we present theoretical evidence, using rigid docking in tandem with molecular dynamics (MD) simulations, which shows that differences in flexibility of TcAChE and mammalian AChEs can account for the striking differences experimentally observed in their rates of inhibition by both sulfonylating and carbamylating agents [13, $17,18]$. Thus, reliance on docking data alone in the context of drug design has the potential to produce very misleading results. 


\section{Results:}

\subsection{Structural Comparison of $T c \mathrm{AChE}$ and $\mathrm{mAChE}$.}
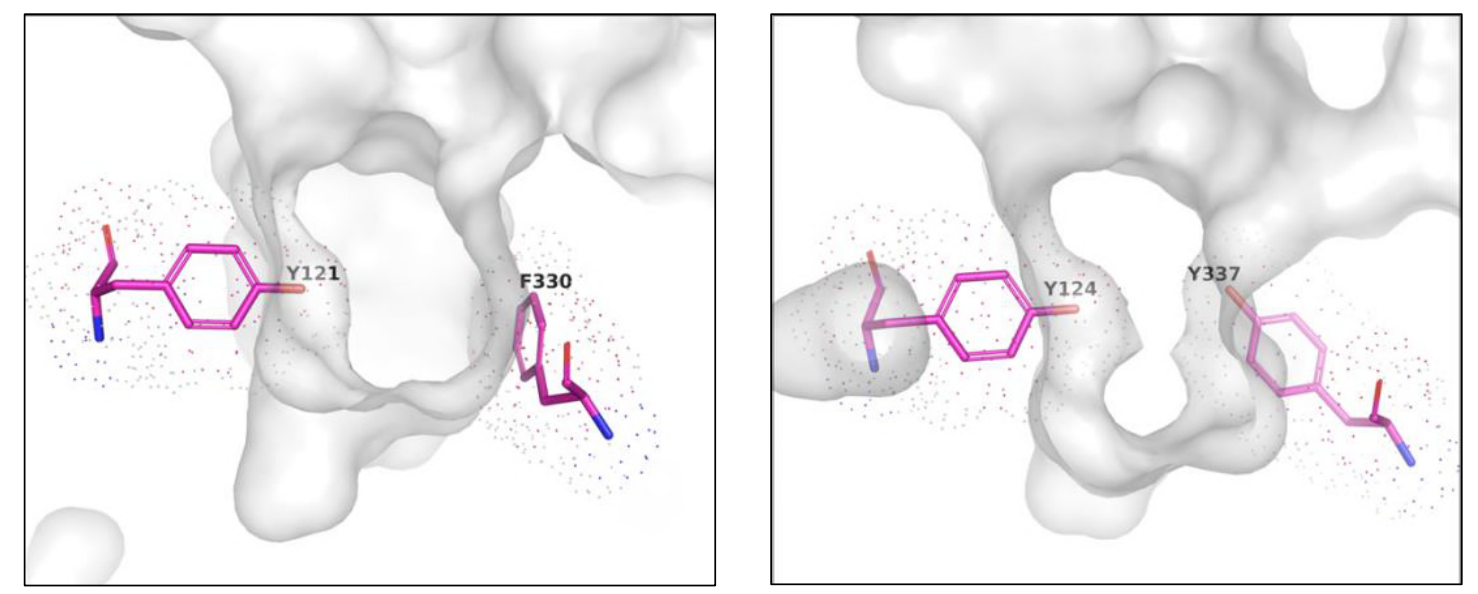

Fig 3. Comparison of the 3D structures of $T c \mathrm{AChE}$ and $\mathrm{mAChE}$ in the bottleneck region of the active-site gorge after performance of the protein preparation protocol. The two panels show the orientations of the bottleneck residues Y121(Y124)/F330(Y337) of TcAChE (left) and $\mathrm{mAChE}$ (right).

The overall structures of the two enzymes closely resemble each other, with RMSD values of $\mathrm{C} \alpha$ atoms $0.54 \AA$ for 449 atoms after protein preparation, and $0.54 \AA$, for 434 atoms, for the RSCB pdb structures. However, careful inspection reveals three clear differences between the TcAChE and $\mathrm{mAChE}$ structures:

(i) There is a difference in one residue at the bottleneck of the active-site gorge, F330 in TcAChE being replaced by $\mathrm{Y} 337 \mathrm{in} \mathrm{mAChE}$, with the sidechains of these two residues being oriented very differently (Fig 3).

(ii) In mAChE there are four residues, P258-P259-G260-G261, which are absent in $T c \mathrm{AChE}$ (Fig 4). As a result, a significantly larger loop protrudes in $\mathrm{mAChE}$ than in TcAChE (Fig 5). 
(iii) In addition to the bottleneck residue, four additional residues in the upper portion of the gorge differ in TcAChE and mAChE: E73(T75), Q74(L76), S81(T83), S124(A127).

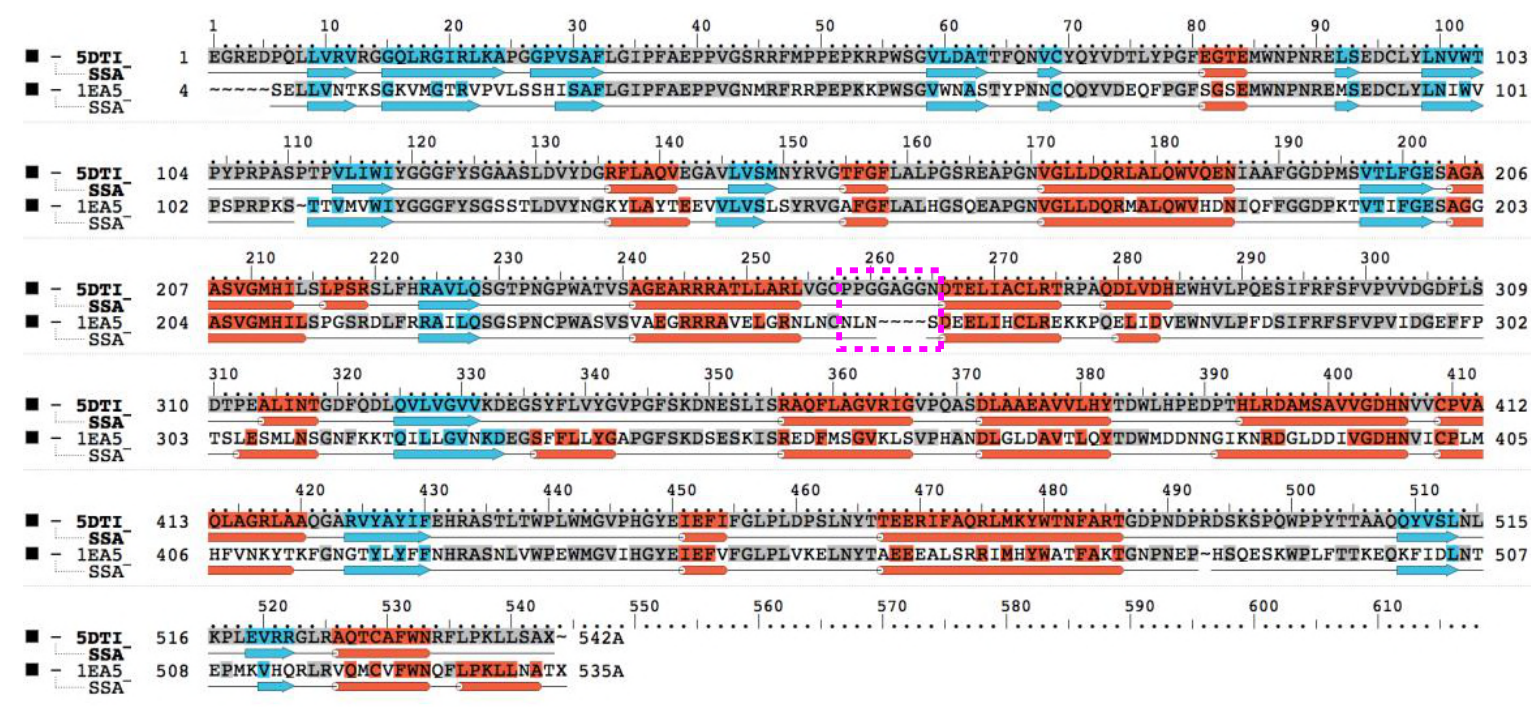

Fig 4. Pairwise structure-based sequence alignment of TcAChE and $\mathrm{mAChE}$ employing the Schrödinger Maestro multiple sequence viewer (MSV) [19]. They possess 58.1\% identity and $74.1 \%$ similarity. The numbers above the alignment correspond to those of the mAChE sequence. The additional loop in mAChE (PPGGAGGN) is highlighted in magenta. The $\alpha$-helices, $\beta$-strands and loops in the structures of TcAChE and $\mathrm{mAChE}$ are represented as cylinders (red), arrows (cyan) and lines (black), respectively. 


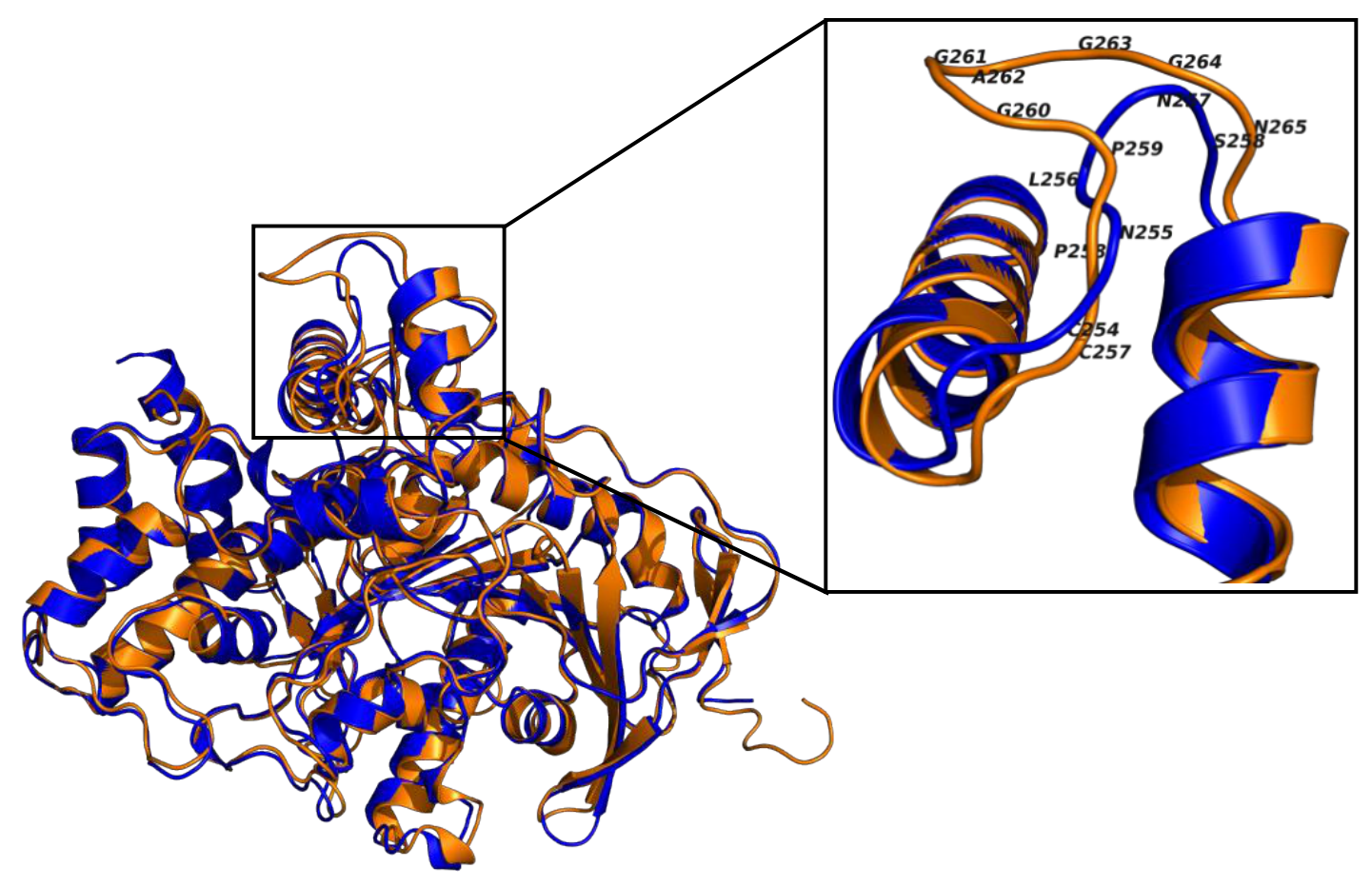

Fig 5. Superposition of cartoon representations of the crystal structures of TcAChE (blue) and $\mathrm{mAChE}$ (orange). The inset (upper right) highlights the large loop present in mAChE.

\subsection{MD simulations of $\mathrm{TcAChE}$ and $\mathrm{mAChE}$.}

Knowledge of the intrinsic flexibility of a protein is important for understanding how structure is linked to function [20]. Accordingly, we performed 20-ns MD simulations on the native crystal structures of $T c \mathrm{AChE}$ and $\mathrm{mAChE}$ (Fig 6). Although the 3D structures are almost identical, the MD simulations clearly reveal that mAChE is significantly more flexible than TcAChE. Fig 6 shows that the average RMSD for the backbone atoms in mAChE is $\sim 1.3 \AA$, compared to $\sim 1.0 \AA$ in $T c \mathrm{AChE}$ (see S2 Fig in Supplementary Information). Almost throughout the entire sequence the mAChE residues are more flexible than those of TcAChE (Fig 7) (see S3 Fig in Supplementary Information). One of the most flexible regions is around the inserted PPGG sequence in $\mathrm{mAChE}$ (Fig 7). 

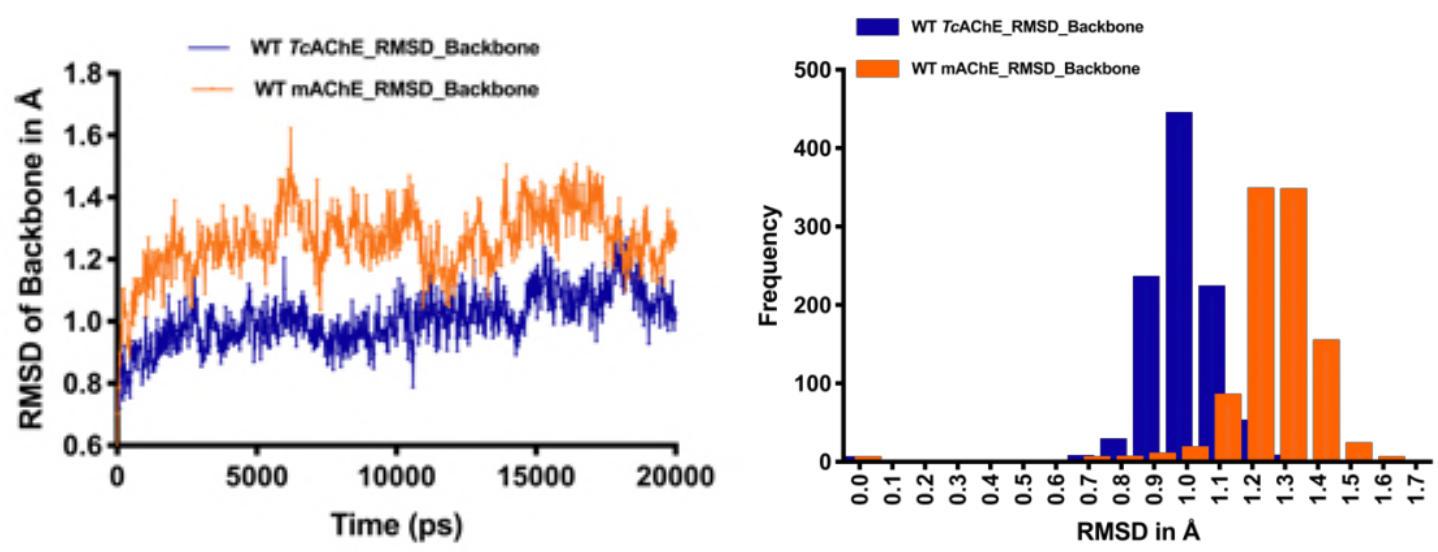

Fig 6. RMSD values for backbone atoms of $\mathrm{mAChE}$ (orange) and $T c \mathrm{AChE}$ (blue) obtained from the 20-ns MD simulations. Left panel, time course of the simulation; right panel, frequency histograms derived by sampling the data displayed on the left at 20-ps intervals.

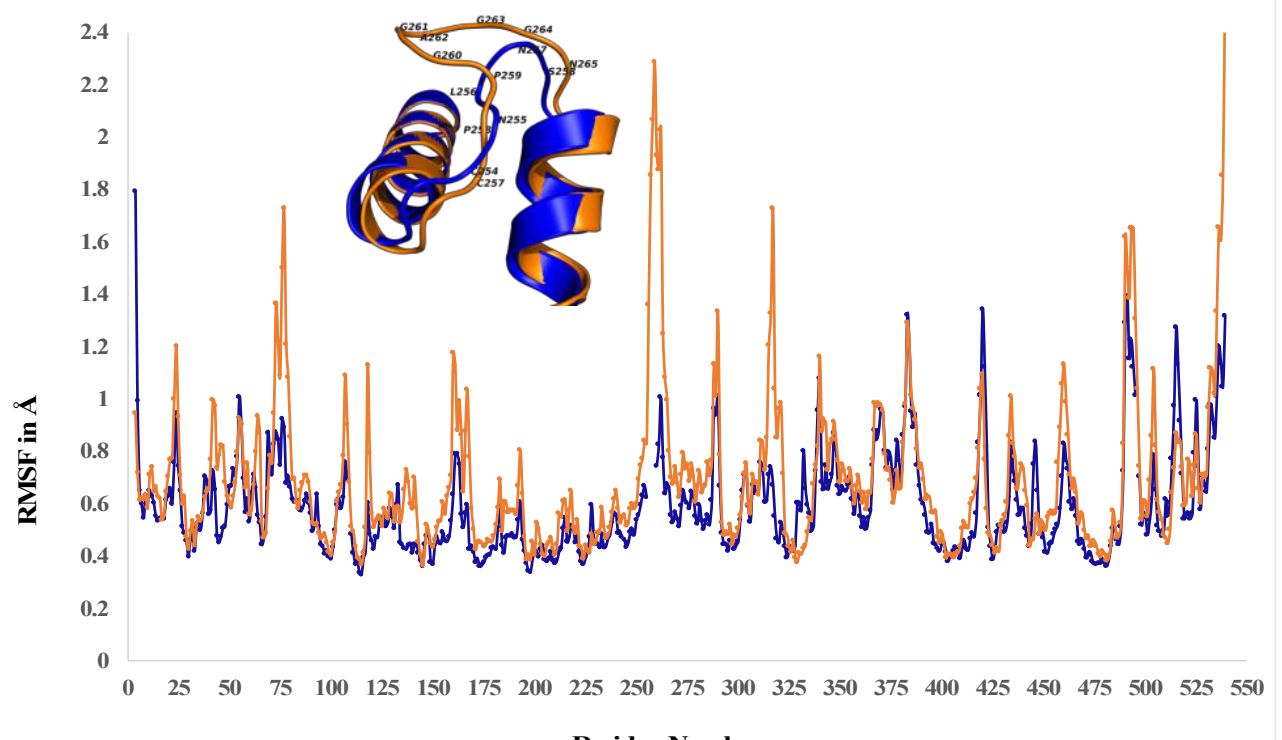

Residue Number

Fig 7. RMSF values for the backbone atoms of $\mathrm{mAChE}$ (orange) and TcAChE (blue) obtained from the 20-ns MD simulations.

Our MD simulations are consistent with those previously published for mAChE [21] and for TcAChE [22] (see S4a Fig and S4b Fig in Supplementary Information). 


\subsection{GlideXP docking of PMSF and BSF into TcAChE and mAChE followed by MD simulation.}

\subsubsection{Docking.}

No crystal structures are available of complexes or conjugates of BSF or PMSF with AChE.

Therefore, GlideXP was used to dock both inhibitors into TcAChE [23] and mAChE [24].

In all four cases, the inhibitors dock at a very similar position (Fig 8), with the electrophilic

sulfur atom remaining at a great distance from the nucleophilic hydroxyl group of S200(S203) within the active site at the bottom of the gorge (Fig 8 and Table 1).

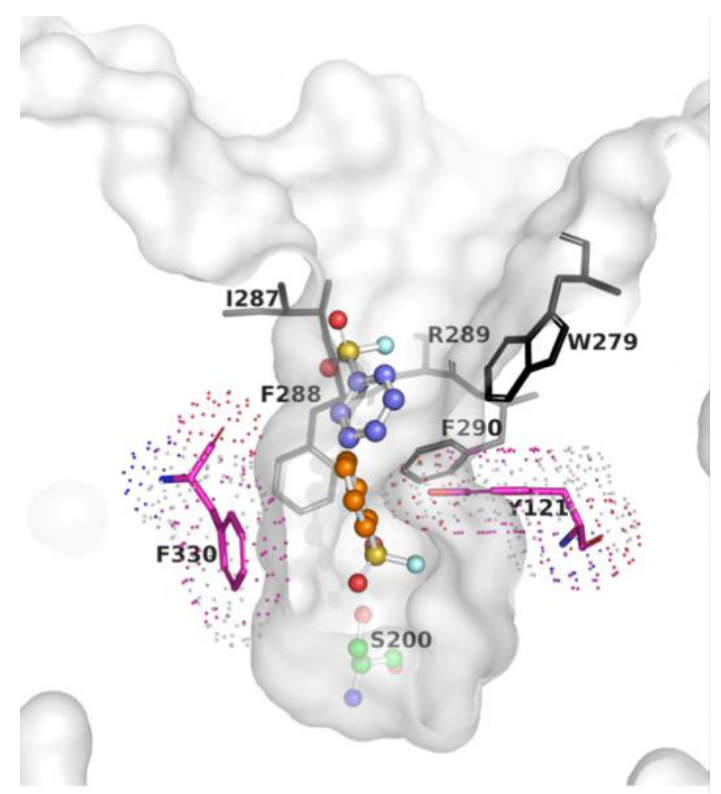

(a)

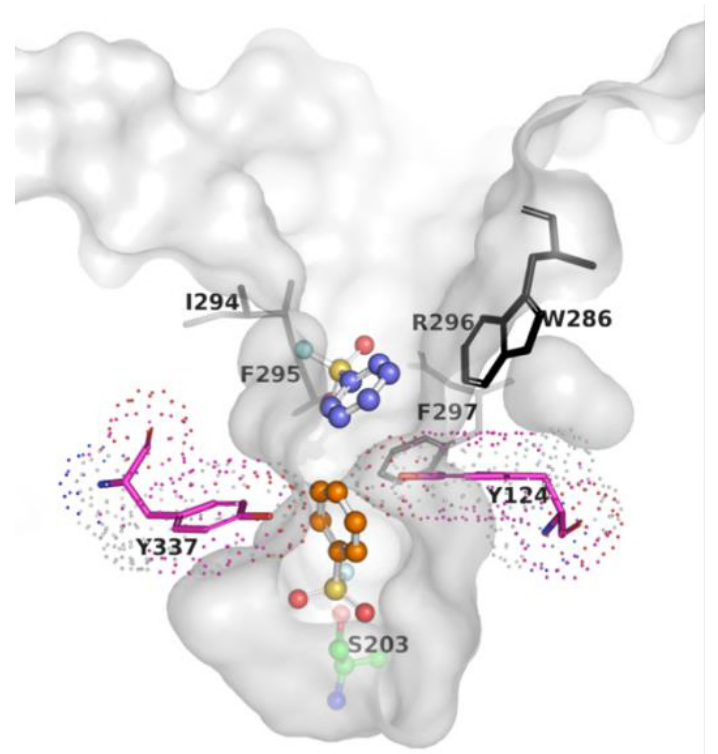

(b) 


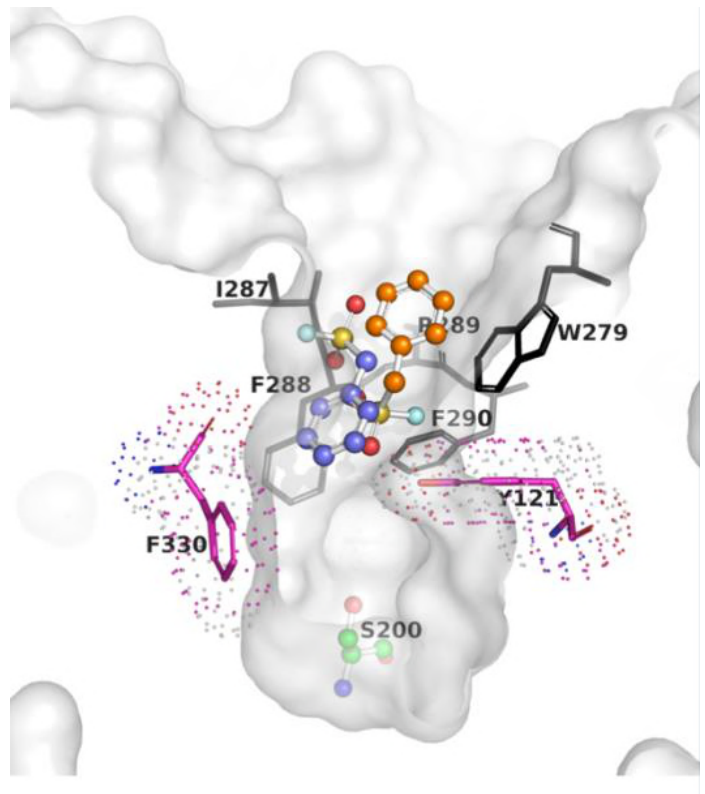

(c)

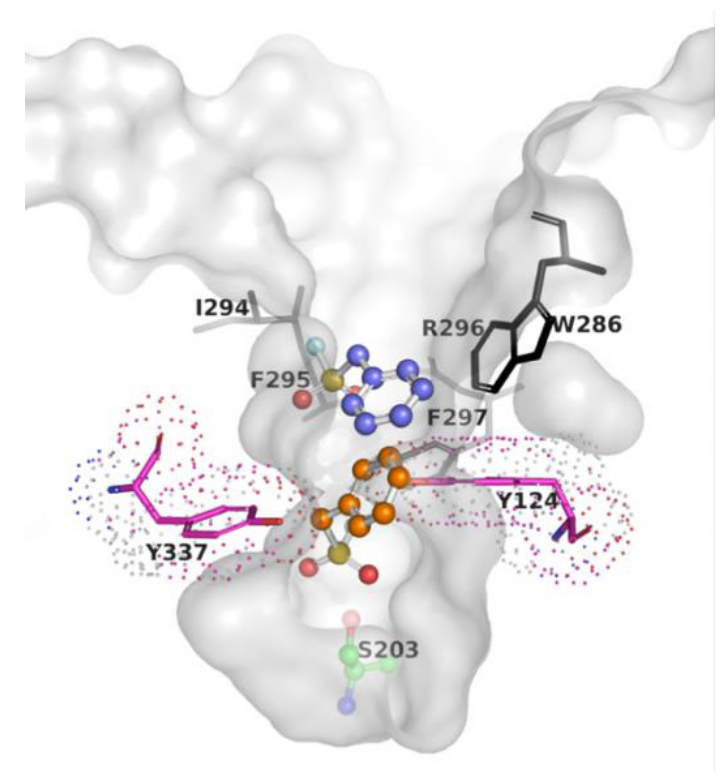

(d)

Fig 8. GlideXP docking and MD simulation for interaction of BSF and PMSF with TcAChE and $\mathrm{mAChE}$. The upper panels show the data obtained for interaction of BSF with (a) TcAChE and (b) mAChE. The lower panels show the data obtained for interaction of PMSF with (c) TcAChE and (d) mAChE. In all four panels two copies of the ligand are displayed. One shows the position of the ligand after docking alone (blue), and the other shows the position after docking followed by MD simulation (orange). It should be noted that the orientations of the amino-acid side-chains displayed are those seen prior to the MD simulations.

\subsubsection{Simulation Following Docking.}

Since BSF inhibits both TcAChE and mAChE, whereas PMSF inhibits only mAChE, the docking results displayed in the previous section obviously do not reflect the experimental data. We decided, therefore, to perform MD simulations following docking $[24,25]$. It can be clearly seen that after the MD simulation BSF approaches close to $\mathrm{S} 200(\mathrm{~S} 203) O \gamma$ in both $T c$ AChE and mAChE. However, PMSF approaches S203O $\gamma$ in mAChE, whereas it

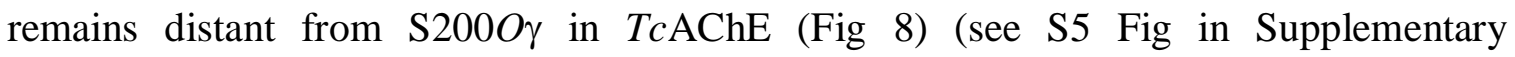
Information). 
Table 1: Distances between S200(S203) $O \gamma$ of $T c \mathrm{AChE}$ and $\mathrm{mAChE}$ and the sulfur atom of BSF or PMSF after docking alone or after docking followed by MD simulation

\begin{tabular}{|c|c|c|c|c|}
\hline & \multicolumn{2}{|c|}{$T c \mathrm{AChE}$} & \multicolumn{2}{c|}{$\mathrm{mAChE}$} \\
\hline & Docked & MD & Docked & $\mathrm{MD}$ \\
\hline BSF & $11.8 \AA$ & $4.5 \AA$ & $10.2 \AA$ & $3.0 \AA$ \\
\hline PMSF & $11.8 \AA$ & $11.2 \AA$ & $10.2 \AA$ & $4.0 \AA$ \\
\hline
\end{tabular}

The MD values displayed refer to the closest approach of the sulfur atom of the ligand to the active-site $\mathrm{S} 200(\mathrm{~S} 203) O \gamma$ throughout the entire MD trajectory.

Figs 9 and 10 displays the MD trajectories for the four cases analyzed, and the histograms derived from them. It can be seen that in the interaction of BSF with TcAChE the ligand approaches S2000 $\gamma$ quite closely for part of the time, whereas PMSF remains much further away, above the bottleneck. In the corresponding histograms for interactions with mAChE, the trajectory for BSF almost merges with the magenta line corresponding to the VDW contact distance, while that for PMSF is a little further away. In all four cases, after docking alone the sulfonyl group points up the gorge, away from the active-site, whereas after docking it points towards the active-site.
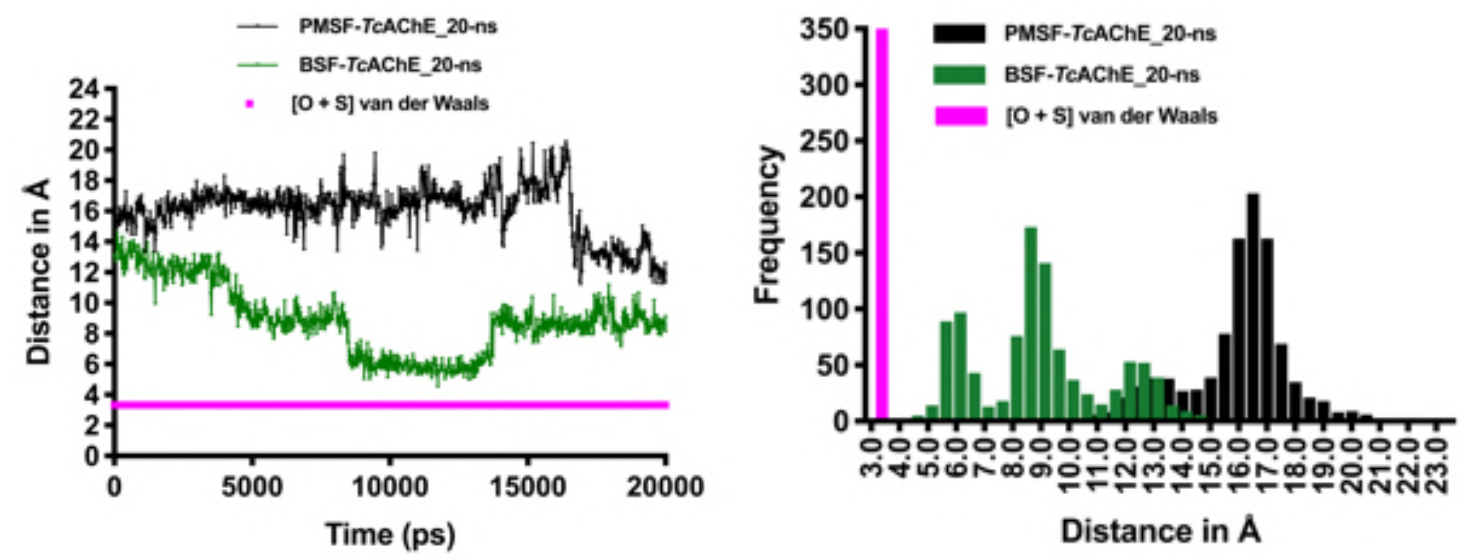
Fig 9. MD trajectories for interaction of PMSF and BSF with TcAChE. Left, 20-ns trajectories showing BSF-TcAChE (green) and PMSF-TcAChE (black); the magenta line represents the minimum distance between the sulfur atom of the inhibitor and S200O $\gamma$ in a productive encounter. Right, frequency histograms derived by sampling the data displayed on the left at 20-ps intervals.
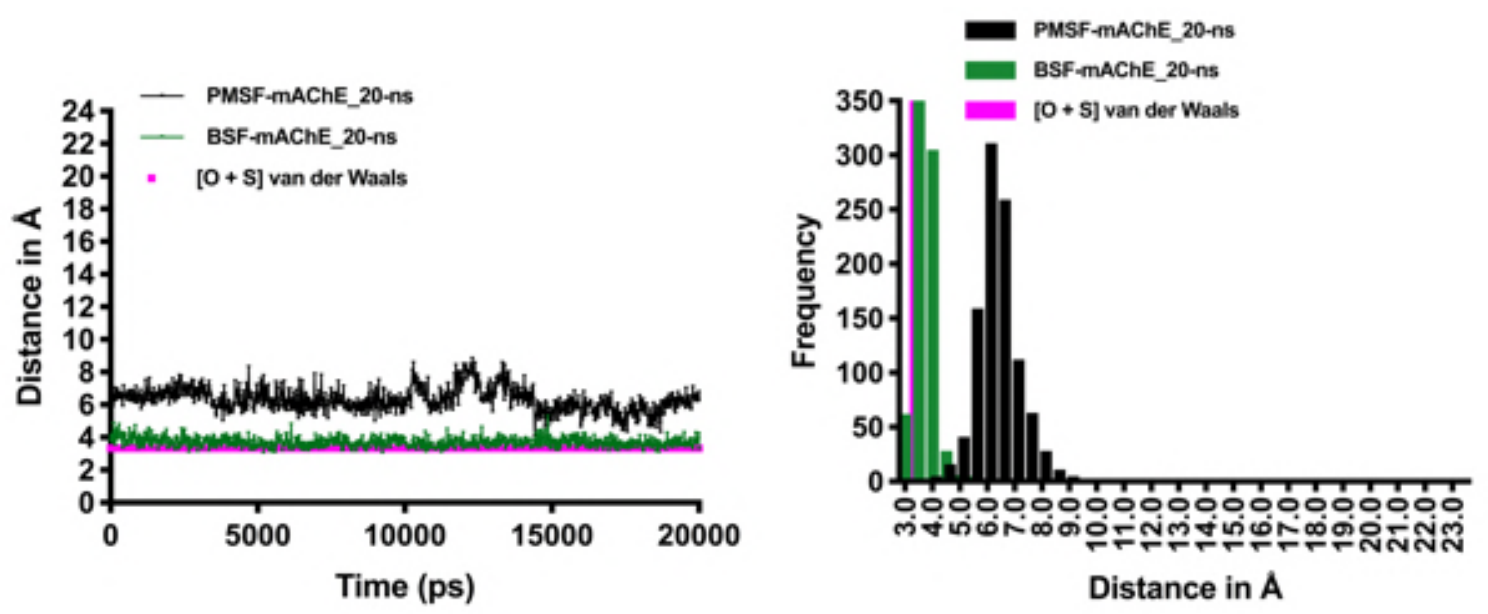

Fig 10. MD trajectories for interaction of PMSF and BSF with mAChE. Left, 20-ns trajectories showing BSF-mAChE (green) and PMSF-mAChE (black); the magenta line represents the minimum distance between the sulfur atom of the inhibitor and $\mathrm{S} 203 \mathrm{O} \gamma$ in a productive encounter. Right, frequency histograms derived by sampling the data displayed on the left at 20 -ps intervals.

\section{Discussion:}

As mentioned in the Introduction, TcAChE, mAChE, and human (h) AChE, act at similar rates on their natural substrate, ACh, and on its homolog, ATCh. They have high sequence homology, and their crystal structures reveal almost identical folds. Yet at least two covalent inhibitors interact several orders of magnitude more rapidly with the mammalian enzymes than with $T c \mathrm{AChE}[13,17]$. It was on this issue that our theoretical study focused. Since $T c \mathrm{AChE}$ and the mammalian enzymes do not differ appreciably in their 3D structures [26], steric factors do not seem to explain these very large differences. Consequently, we 
considered the possibility that differences in their dynamics might provide an explanation.

However, it should be kept in mind that, whereas BSF has a planar geometry (Scheme 1), PMSF has a non-planar geometry due to the presence of the additional methylene group, so that its movement through the bottleneck might be expected to be more restricted than that of BSF.

Figs 6 and 7 clearly show large differences in flexibility between $T c \mathrm{AChE}$ and mAChE. mAChE is much more flexible than TcAChE along most of the polypeptide chain, displaying an RMSD for backbone atoms of $1.3 \AA$ vs $1.0 \AA$ for TcAChE. Particularly high flexibility is seen for a loop that includes residues P258-P259-G260-G261, which are absent in TcAChE (Figs $6 \& 7$ ). We thus considered it plausible that this increased flexibility of the mAChE might permit movement of the PMSF through the bottleneck that would not occur in TcAChE.

The results of docking and MD simulations of the WT enzymes by BSF and PMSF mimic the experimental data; thus, BSF comes close to the active-site serine $O \gamma$ atom in both AChEs, but while this is also the case for PMSF binding to $\mathrm{mAChE}$, for TcAChE it remains above the bottleneck, near the top of the gorge, close to the position it occupied in the docking protocol alone.

It should be noted that in all cases, after docking alone both PMSF and BSF were oriented with their sulfonyl moiety pointing up the gorge, away from the active site. But when docking was followed by the MD protocol, in all cases the molecule flipped $\sim 180^{\circ}$, so that 
the sulfonyl moiety pointed towards the active-site $\mathrm{S} 200(\mathrm{~S} 203) O \gamma$. This was true also for PMSF interacting with TcAChE, even though in this case the ligand did not cross the bottleneck. In the crystal structure of S203A mAChE referred to in the Introduction (PDB ID 2HA4) [6] two copies of the substrate, ACh, are seen, one below the bottleneck, and one trapped above it. That trapped above it is oriented, like PMSF and BSF after docking followed by MD simulation, with its leaving group facing into the bottleneck, and its quaternary group making a $\pi$-cation interaction with W286 in the peripheral anionic site.

Experimental mutagenesis studies that we performed earlier also suggested that breathing motions might be involved in controlling access of PMSF to the active site. The double mutation, F288L/F290V, which enlarges the acyl pocket, thus permitting TcAChE to act on butyrylthiocholine [27], renders it even more susceptible to PMSF than the WT enzyme [13]. Furthermore, the L282A mutation, which has lower thermal stability than the WT enzyme [28], is inactivated by PMSF at a rate similar to that at which it inactivates the F288L/F290V mutant $[13,29]$. Thus, in several cases increased flexibility of AChE appears to be associated with the capacity to be inhibited by PMSF.

As mentioned in the Introduction, the carbamylating agent, rivastigmine, inactivates hAChE (which is highly homologous to mAChE, even more so than TcAChE) three orders of magnitude faster than it inactivates $T c \mathrm{AChE}$ [17]. However, various organophosphates (OPs) do not display such differences in rates of phosphorylation of TcAChE and hAChE. Thus, the rates of inactivation of $T c \mathrm{AChE}$ and $\mathrm{hAChE}$ by diisopropylphosphorofluoridate (DFP) are quite similar [30], and the potent $S$ isomers of VX and Russian VX actually 
inactivate $T c \mathrm{AChE}$ a few-fold faster than hAChE (Y. Ashani, personal communication). Another interesting case for comparison is that of (-)-huperzine A (HupA). This is a bulky alkaloid with a rigid structure and diameter of $9.8 \AA$. Although HupA is a reversible inhibitor, it inhibits $\mathrm{AChE}$ with extremely slow rates of association and disassociation [31]. MD and steered MD simulations show that sizeable distortions of the residues along the active-site gorge are required for it to pass the bottleneck [32-34]. Yet the rates of inhibition of $T c \mathrm{AChE}$ and hAChE by HupA are very similar [31]. It is obvious that our understanding of how protein function is coupled to protein dynamics is inadequate, to say the least.

\section{Methods:}

\subsection{Docking Simulations.}

The crystal structures of Torpedo californica acetylcholinesterase (TcAChE, PDB ID: 1EA5 [35, 22], $1.8 \AA$ A resolution) and mouse acetylcholinesterase (mAChE, PDB ID: 5DTI [36], $2.0 \AA$ resolution) were retrieved from the RCSB Protein Data Bank (http://www.rcsb.org). The monomers of Chain A were used for all the simulations [37].

Protein Preparation for Docking and Molecular Dynamics: The 1EA5 and 5DTI structures were prepared with Protein Preparation Wizard [38, 39] in Maestro-v11.1 [40] prior to grid-based-ligand docking (GLIDE) [41, 42] and MD studies, with the following modifications:

- All waters and cofactors were removed.

- Assignment of bond orders

- Addition of hydrogen atoms

- Indicating the 3 intramolecular disulfide bonds 
- Adding unseen atoms of side chains in both TcAChE and mAChE

- Addition of residues 259-264 (PGGAGG) which are not seen in any mAChE crystal structure

- The $\mathrm{N}$ and C-termini were capped with acetyl (ACE) and N-methyl-amino (NMA) groups, respectively

- Assignment of ionization states

- All-atom restrained molecular mechanics (MM) minimizations was performed with a termination criterion of $0.18 \AA$ on the heavy (non-hydrogen) atoms by employing the OPLS3 force field [43]

Ligand preparation: Geometries of the two inhibitors, BSF and PMSF, were optimized using the PBE0 hybrid density functional method $[44,45]$ combined with the cc-pVTZ Gaussian basis set [46]. Calculations were performed with water as the solvent, using the SCRF continuum solvation model [47]. All calculations utilized the Gaussian 09 suite [48]. The parameters of BSF and PMSF were assigned using the OPLS3 force field [43] with the LigPrep [49] tool available in the Schrödinger suite.

Grid Preparation: Due to the large dimensions of the active-site gorge of AChE, we changed the Glide grid box sizes from the default values [50] (see S6 Fig in Supplementary Information) shown in Fig 11a to those shown in Fig 11b, to ensure that all ligand poses would be located within the purple box. "The outer, purple box defines the volume in which the grid potentials are computed. All ligand atoms of a valid pose must be located within this outer box. The inner, green box defines the volume that the ligand center explores during the exhaustive site-point search" (https://www.schrodinger.com/kb/701). 


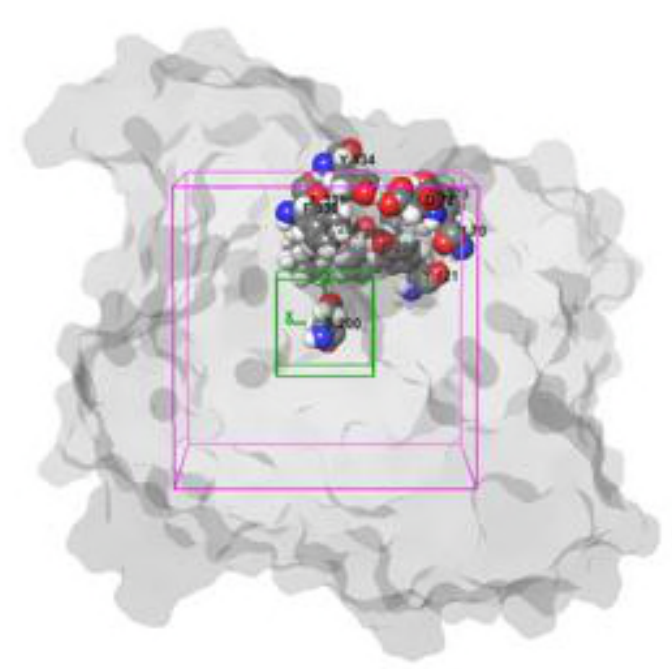

(a)

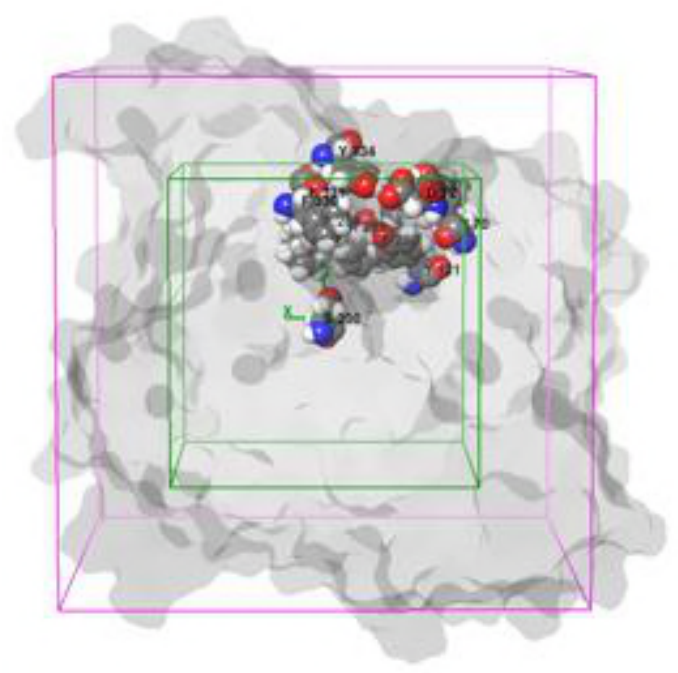

(b)

Fig 11. Glide grid box settings employed: The boxes were centered around S200(S203) ${ }^{1}$, the active-site serine at the bottom of the gorge. (a) Default settings of the inner (green)

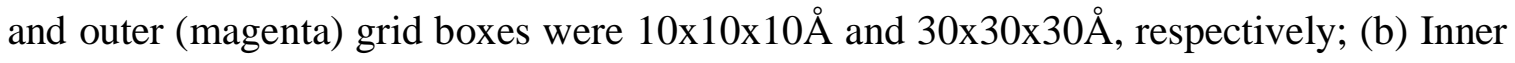
and outer grid box settings employed for the docking studies on TcAChE and mAChE were

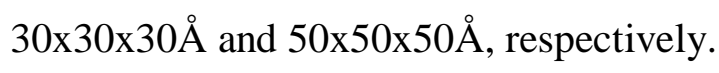

Glide Docking: Docking, with a rigid protein structure and a flexible ligand, was performed using Schrödinger Glide-v7.4, employing the XP (extra precision) option [42].

One hundred poses were generated per docking calculation. In order to soften the potential for non-polar atoms of the protein (within the grid points) and the ligands, their VDW radii were scaled to $1.0 \AA$, with a partial charge cut-off of 0.25 units, while VDW radii of remaining atoms were not scaled (see S7 Fig in Supplementary Information). Glide docking uses a hierarchical clustering algorithm to produce the best set of ligand-binding

\footnotetext{
${ }^{1}$ Throughout the text, when reference is made to amino acid residues in both $T c \mathrm{AChE}$ and mAChE, the $T c \mathrm{AChE}$ residue appears first, followed by the corresponding $\mathrm{mAChE}$ residue in brackets, e.g., S200(S203).
} 
locations in the defined receptor grid space. The lowest XP glide score, for a given ligand, indicates the highest binding affinity for the enzyme.

\subsection{Molecular Dynamics Simulations.}

The Desmond-v4.9 [51] simulation package from Schrödinger was used for all MD simulations. The protein-ligand complex systems were solvated using the explicit SPC [52] solvent model in a 10x10x10 ̊ box, employing the OPLS3 force field [43] (see S8 Fig in Supplementary Information). The charge of the system was neutralized by adding $0.15 \mathrm{M}$ $\mathrm{NaCl}$. The Desmond standard NPT relaxation protocol was used, except that the equilibration time was extended from 24 ps to 5 ns [53] (see S9 Fig in Supplementary Information). After the equilibration step, $20 \mathrm{~ns}$ MD simulations were performed (see S10 Fig in Supplementary Information ). The simulations were run on the Faculty of Chemistry HPC (High-Performance Computing) Facility at the Weizmann Institute of Science.

\section{Supporting Information:}

S1 Fig. Cartesian coordinates, in $\AA$, of the two inhibitors, BSF and PMSF, were optimized using the PBE0 hybrid density functional method combined with the cc-pVTZ Gaussian basis set in aqueous phase, as described in the paper.

S2 Fig. RMSD values, in $\AA$, for backbone atoms of mAChE and TcAChE obtained from the 20-ns MD simulations (see Fig 6 in paper).

S3 Fig. RMSF values, in $\AA$, for the backbone atoms of $\mathrm{mAChE}$ and $T c \mathrm{AChE}$ obtained from the 20-ns MD simulations (see Fig 7 in the paper).

S4a Fig. (a) RMSD of all heavy atoms (blue) and $\mathrm{C} \alpha$ atoms (orange) from the native mAChE structure over a 20-ns MD simulation with OPLS3 force field at 20-ps time 
intervals in the trajectory. (b) Time dependence of RMSD deviations of all heavy atoms (A) and $\mathrm{C} \alpha$ atoms (B) from the crystal structure of mAChE [21]. The thick line represents the unliganded simulation, and the thin line represents the liganded (huperzine A) simulation. (c) RMSD of all heavy atoms (blue) and $\mathrm{C} \alpha$ atoms (orange) from the native structure for the first ns of the traces shown in (a).

S4b Fig. (a) RMSF of C $\alpha$ atoms of unliganded TcAChE in a 20-ns MD simulation using the OPLS3 force field, Nose-Hoover chain thermostat and Martyna-Tobias-Klein barostat, as in the body of the text; (b) RMSF of $\mathrm{C} \alpha$ atoms of unliganded TcAChE [22] in a 20-ns MD simulation using the GROMOS96 force field, Berendsen thermostat and Berendsen barostat.

S5 Fig. Distances, in $\AA$, between $\mathrm{S} 200(\mathrm{~S} 203) O \gamma$ of $T c \mathrm{AChE}$ and $\mathrm{mAChE}$ and the sulfur atom of BSF or PMSF after docking followed by MD simulation.

S6 Fig. Grid box parameters in the GLIDE docking program.

S7 Fig. The ligand docking parameters in the GLIDE XP docking program.

S8 Fig. The parameters for adding solvent to the ligand-protein complexes.

S9 Fig. Protocol and parameters of NPT relaxation after adding solvents to the docked ligand-protein complex.

S10 Fig. Protocol and parameters of NPT Production MD simulations after NPT relaxation processes

\section{Acknowledgments:}

JMLM acknowledges funding from the Israel Science Foundation (grant 1358/15) and from the Weizmann Institute's SABRA (Supporting Advanced Basic Research) program, 
the latter supported by a grant from the Estate of Emile Mimran. The funders had no role in study design, data collection and analysis, decision to publish, or preparation of the manuscript. We thank Prof. Koby Levy and Dr. Chakrapani Subramanyam for valuable discussions.

\section{Author Contributions:}

Conceptualization: Israel Silman, Joel L. Sussman, Nellore Bhanu Chandar.

Formal analysis: Nellore Bhanu Chandar, Irena Efremenko.

Funding acquisition: Jan M.L. Martin.

Investigation: Nellore Bhanu Chandar, Irena Efremenko, Israel Silman, Jan M.L. Martin, Joel L. Sussman.

Methodology: Nellore Bhanu Chandar, Irena Efremenko.

Project administration: Jan M.L. Martin.

Supervision: Israel Silman, Jan M.L. Martin, Joel L. Sussman.

Validation: Israel Silman, Jan M.L. Martin, Joel L. Sussman.

Visualization: Joel L. Sussman.

Writing - original draft: Nellore Bhanu Chandar, Joel L. Sussman, Israel Silman.

Writing - review \& editing: Nellore Bhanu Chandar, Joel L. Sussman, Israel Silman, Jan M.L. Martin.

\section{REFERENCES}

1. Legay C. Why so many forms of acetylcholinesterase?. Microscopy Research and Technique. 2000;49: 56-72. https://doi.org/10.1002/(SICI)10970029(20000401)49:1\%3C56::AID-JEMT7\%3E3.0.CO;2-R 
2. Rotundo RL. Expression and localization of acetylcholinesterase at the neuromuscular junction. Journal of Neurocytology. 2003;32: 743-766. https://doi.org/10.1023/B:NEUR.0000020621.58197.d4

3. Bazelyansky M, Robey E, Kirsch JF. Fractional diffusion-limited component of reactions catalyzed by acetylcholinesterase. Biochemistry. 1986;25: 125-130. https://doi.org/10.1021/bi00349a019

4. Sussman JL, Harel M, Frolow F, Oefner C, Goldman A, Toker L, et al. Atomic structure of acetyicholinesterase from Torpedo californica : a prototypic acetyicholine-binding protein. Science. 1991;253: 872-879. http://doi.org/10.1126/science.1678899

5. Shen T, Tai K, Henchman RH, McCammon JA. Molecular dynamics of acetylcholinesterase. Accounts of Chemical Research. 2002;35: 332-340. https://doi.org/10.1021/ar010025i

6. Bourne Y, Radic' Z, Sulzenbacher G, Kim E, Taylor P, Marchot P. Substrate and product trafficking through the active center gorge of acetylcholinesterase analyzed by crystallography and equilibrium binding. Journal of Biological Chemistry. 2006; 281: 29256-29267. https://doi.org/10.1074/jbc.M603018200

7. Millard CB, Broomfield CA. Anticholinesterases : Medical applications of neurochemical principles. Journal of Neurochemistry. 1995;64: 1909-1918. https://doi.org/10.1046/j.1471-4159.1995.64051909.x

8. Le T, Lee HJ, Jin HJ. An efficient method to eliminate the protease activity contaminating commercial bovine pancreatic DNase I. Analytical Biochemistry. 2015;483: 4-6. https://doi.org/10.1016/j.ab.2015.04.030 
9. Fahrney DE, Gold AM. Sulfonyl fluorides as inhibitors of esterases. I. Rates of reaction with acetylcholinesterase, $\alpha$-chymotrypsin, and trypsin. Journal of the American Chemical Society. 1963;85: 997-1000.

https://doi.org/10.1021/ja00890a037

10. Barnett P, Rosenberry TL. Inactivation of Electrophorus electricus acetylcholinesterase by benzenemethane sulfonylfluoride. Archives of Biochemistry and Biophysics. 1978;190: 202-205. https://doi.org/10.1016/00039861(78)90268-0

11. Turini P, Kurooka S, Steer M, Corbascio AN, Singer TP. The action of phenylmethylsulfonyl fluoride on human acetylcholinesterase, chymotrypsin and trypsin. Journal of Pharmacology and Experimental Therapeutics. 1969;167: 98104. http://jpet.aspetjournals.org/content/167/1/98

12. Moss DE, Fahrney D. Kinetic analysis of differences in brain acetylcholinesterase from fish or mammalian sources. Biochemical Pharmacology. 1978;27: 26932698. https://doi.org/10.1016/0006-2952(78)90044-8

13. Kraut D, Goff H, Pai RK, Hosea NA, Silman I, Sussman JL, et al. Inactivation studies of acetylcholinesterase with phenylmethylsulfonyl fluoride. Molecular Pharmacology. 2000;57: 1243-1248.

http://molpharm.aspetjournals.org/content/57/6/1243

14. Bourne Y, Taylor P, Bougis PE, Marchot P. Crystal structure of mouse acetylcholinesterase. a peripheral site-occluding loop in a tetrameric assembly. Journal of Biological Chemistry. 1999;274: 2963-2970.

http://doi.org/10.1074/jbc.274.5.2963 
15. Vigny M, Bon S, Massoulié J, Leterrier F. Active-site catalytic efficiency of acetylcholinesterase molecular forms in Electrophorus, Torpedo, rat and chicken. European Journal of Biochemistry. 1978;85: 317-323. https://doi.org/10.1111/j.1432-1033.1978.tb12241.x

16. Vellom DC, Radić Z, Li Y, Pickering NA, Camp S, Taylor P. Amino acid residues controlling acetylcholinesterase and butyrylcholinesterase specificity. Biochemistry. 1993;32: 12-17. https://doi.org/10.1021/bi00052a003

17. Bar-On P, Millard CB, Harel M, Dvir H, Enz A, Sussman JL, et al. Kinetic and structural studies on the interaction of cholinesterases with the anti-Alzheimer drug rivastigmine. Biochemistry. 2002;41: 3555-3564.

https://doi.org/10.1021/bi020016x

18. Ali MR, Sadoqi M, Møller SG, Boutajangout A, Mezei M. Assessing the binding of cholinesterase inhibitors by docking and molecular dynamics studies. Journal of Molecular Graphics and Modelling. 2017;76: 36-42. https://doi.org/10.1016/j.jmgm.2017.06.027

19. Multiple sequence viewer developed by J Jusuf and S Krystek as implemented in the Schrodinger package of programs, Schrödinger, LLC, New York, NY, 2017.

20. Eastman P, Pellegrini M, Doniach S. Protein flexibility in solution and in crystals. Journal of Chemical Physics. 1999;110: 10141-10152. https://doi.org/10.1063/1.478887

21. Tara S, Straatsma TP, McCammon JA. Mouse acetylcholinesterase unliganded and in complex with huperzine A: a comparison of molecular dynamics simulations. Biopolymers. 1999;50: 35-43. https://doi.org/10.1002/(SICI)1097- 


\section{2(199907)50:1<35::AID-BIP4>3.0.CO;2-6}

22. Xu Y, Colletier JP, Weik M, Jiang H, Moult J, Silman I, et al. Flexibility of aromatic residues in the active-site gorge of acetylcholinesterase: X-ray versus molecular dynamics. Biophysical Journal. 2008;95: 2500-2511. https://doi.org/10.1529/biophysj.108.129601

23. Pang YP, Kozikowski AP. Prediction of the binding site of 1-benzyl-4-[(5,6dimethoxy-1-indanon-2-yl)methyl]piperidine in acetylcholinesterase by docking studies with the SYSDOC program. Journal of Computer-Aided Molecular Design. 1994;8: 683-693. https://doi.org/10.1007/BF00124015

24. Tara S, Helms V, Straatsma TP, McCammon JA. Molecular dynamics of mouse acetylcholinesterase complexed with huperzine A. Biopolymers. 1999;50: 347359.

https://doi.org/10.1002/(SICI)1097-0282(19991005)50:4<347::AID$\underline{\mathrm{BIP} 1>3.0 . \mathrm{CO} ; 2-\mathrm{R}}$

25. Alonso H, Bliznyuk AA, Gready JE. Combining docking and molecular dynamic simulations in drug design. Medicinal Research Reviews. 2006;26: 531-568. https://doi.org/10.1002/med.20067

26. Kryger G, Harel M, Giles K, Toker L, Velan B, Lazar A, et al. Structures of recombinant native and E202Q mutant human acetylcholinesterase complexed with the snake-venom toxin fasciculin-II. Acta Crystallographica Section D Biological Crystallography. 2000;56: 1385-1394.

https://doi.org/10.1107/S0907444900010659 
27. Harel M, Sussman JL, Krejci E, Bon S, Chanal P, Massoulié J, et al. Conversion of acetylcholinesterase to butyrylcholinesterase: modeling and mutagenesis.

Proceedings of the National Academy of Sciences of the United States of America. 1992;89: 10827-10831. https://doi.org/10.1073/pnas.89.22.10827

28. Morel N, Bon S, Greenblatt HM, Van Belle D, Wodak SJ, Sussman JL, et al. Effect of mutations within the peripheral anionic site on the stability of acetylcholinesterase. Molecular Pharmacology. 1999;55: 982-992. https://doi.org/10.1124/mol.55.6.982

29. Kraut D, Morel N, Bon S, Massoulié J, Silman I, Sussman JL, et al. Torpedo AChE L282A mutant (destabilized) becomes PMSF sensitive. Biochemistry. 2000;39: 1547. http://doi.org/10.1021/bi9950995

30. Millard CB, Kryger G, Ordentlich A, Greenblatt HM, Harel M, Raves ML, et al. Crystal structures of aged phosphonylated acetylcholinesterase: nerve agent reaction products at the atomic level. Biochemistry. 1999;38: 7032-7039. https://doi.org/10.1021/bi9826781

31. Ashani Y, Grunwald J, Kronman C, Velan B, Shafferman A. Role of tyrosine 337 in the binding of huperzine A to the active site of human acetylcholinesterase. Molecular Pharmacology. 1994;45: 555-560. http://molpharm.aspetjournals.org/content/45/3/555.long

32. Xu Y, Shen J, Luo X, Silman I, Sussman JL, Chen K, et al. How does huperzine A enter and leave the binding gorge of acetylcholinesterase? Steered molecular dynamics simulations. Journal of the American Chemical Society. 2003;125:

11340-11349. https://doi.org/10.1021/ja029775t 
33. Bai F, Xu Y, Chen J, Liu Q, Gu J, Wang X, et al. Free energy landscape for the binding process of Huperzine A to acetylcholinesterase. Proceedings of the National Academy of Sciences of the United States of America. 2013;110: 4273 4278. https://doi.org/10.1073/pnas.1301814110

34. Rydzewski J, Jakubowski R, Nowak W, Grubmüller H. Kinetics of huperzine A dissociation from acetylcholinesterase via multiple unbinding pathways. Journal of Chemical Theory and Computation. 2018;14: 2843-2851.

https://doi.org/10.1021/acs.jctc.8b00173

35. Dvir H, Jiang HL, Wong DM, Harel M, Chetrit M, He XC, et al. X-ray structures of Torpedo californica acetylcholinesterase complexed with (+)-huperzine A and (-)-huperzine B: structural evidence for an active site rearrangement.

Biochemistry. 2002;41: 10810-10818. https://doi.org/10.1021/bi020151\%2B

36. Katz FS, Pecic S, Tran TH, Trakht I, Schneider L, Zhu Z, et al. Discovery of new classes of compounds that reactivate acetylcholinesterase inhibited by organophosphates. ChemBioChem. 2015;16: 2205-2215.

https://doi.org/10.1002/cbic.201500348

37. Cheng S, Song W, Yuan X, Xu Y. Gorge motions of acetylcholinesterase revealed by microsecond molecular dynamics simulations. Scientific Reports. 2017;7:

3219(1-12). https://doi.org/10.1038/s41598-017-03088-y

38. Sastry GM, Adzhigirey M, Day T, Annabhimoju R, Sherman W. Protein and ligand preparation: parameters, protocols, and influence on virtual screening enrichments. Journal of Computer-Aided Molecular Design. 2013;27: 221-234. https://doi.org/10.1007/s10822-013-9644-8 
39. Schrödinger Release 2017-1: Schrödinger Suite 2017-1 Protein Preparation Wizard; Epik, Schrödinger, LLC, New York, NY, 2017; Impact, Schrödinger, LLC, New York, NY, 2017; Prime, Schrödinger, LLC, New York, NY, 2017.

40. Schrödinger Release 2017-1: Maestro, Schrödinger, LLC, New York, NY, 2017.

41. Friesner RA, Banks JL, Murphy RB, Halgren TA, Klicic JJ, Mainz DT, et al. Glide: a new approach for rapid, accurate docking and scoring. 1. Method and assessment of docking accuracy. Journal of Medicinal Chemistry. 2004;47: 17391749. https://doi.org/10.1021/jm0306430

42. Friesner RA, Murphy RB, Repasky MP, Frye LL, Greenwood JR, Halgren TA, et al. Extra precision glide: docking and scoring incorporating a model of hydrophobic enclosure for protein-ligand complexes. Journal of Medicinal Chemistry. 2006;49: 6177-6196. https://doi.org/10.1021/jm051256o

43. Harder E, Damm W, Maple J, Wu C, Reboul M, Xiang JY, et al. OPLS3: a force field providing broad coverage of drug-like small molecules and proteins. Journal of Chemical Theory and Computation. 2016;12: 281-296.

https://doi.org/10.1021/acs.jctc.5b00864

44. Perdew JP, Burke K, Ernzerhof M. Generalized gradient approximation made simple. Physical Review Letters. 1996;77: 3865-3868. https://doi.org/10.1103/PhysRevLett.77.3865

45. Perdew JP, Burke K, Ernzerhof M. Errata: generalized gradient approximation made simple [Phys. Rev. Lett. 77, 3865 (1996)]. Physical Review Letters.

1997;78: 1396. https://doi.org/10.1103/PhysRevLett.78.1396 
46. Dunning TH Jr. Gaussian basis sets for use in correlated molecular calculations. I.

The atoms boron through neon and hydrogen. Journal of Chemical Physics.

1989;90: 1007-1023. https://doi.org/10.1063/1.456153

47. Cossi M, Scalmani G, Rega N, Barone V. New developments in the polarizable continuum model for quantum mechanical and classical calculations on molecules in solution. Journal of Chemical Physics. 2002;117: 43-54.

https://doi.org/10.1063/1.1480445

48. Frisch MJ, Trucks GW, Schlegel HB, Scuseria GE, Robb MA, Cheeseman JR, et al. Gaussian 09, Revision G.01; Gaussian, Inc.: Wallingford, CT, 2009.

49. Schrödinger Release 2017-1: LigPrep, Schrödinger, LLC, New York, NY, 2017.

50. Berg L, Andersson CD, Artursson E, Hörnberg A, Tunemalm AK, Linusson A, et al. Targeting acetylcholinesterase: identification of chemical leads by high throughput screening, structure determination and molecular modeling. PLoS ONE. 2011;6: e26039(1-12). https://doi.org/10.1371/journal.pone.0026039

51. Schrödinger Release 2017-1: Desmond molecular dynamics system, D. E. Shaw Research, New York, NY, 2017. Maestro-Desmond Interoperability Tools, Schrödinger, New York, NY, 2017.

52. Wu Y, Tepper HL, Voth GA. Flexible simple point-charge water model with improved liquid-state properties. Journal of Chemical Physics. 2006;124: 024503(1-12). https://doi.org/10.1063/1.2136877

53. Guo Z, Mohanty U, Noehre J, Sawyer TK, Sherman W, Krilov G. Probing the $\alpha-$ helical structural stability of stapled p53 peptides: molecular dynamics simulations and analysis. Chemical Biology \& Drug Design. 2010;75: 348-359. 
bioRxiv preprint doi: https://doi.ora/10 1101/532754 this version posted Januarv 28,2019 . The copvriaht holder for this preprint (which was not certified by peer review) is the author/funder, who has granted bioRxiv a license to display the preprint in perpetuity. It is made available under aCC-BY 4.0 International license.

https://doi.org/10.1111/j.1747-0285.2010.00951.x 